\title{
Elective endoscopic gallbladder treatment in patient with recurrent gallbladder colic and high surgical risk
}

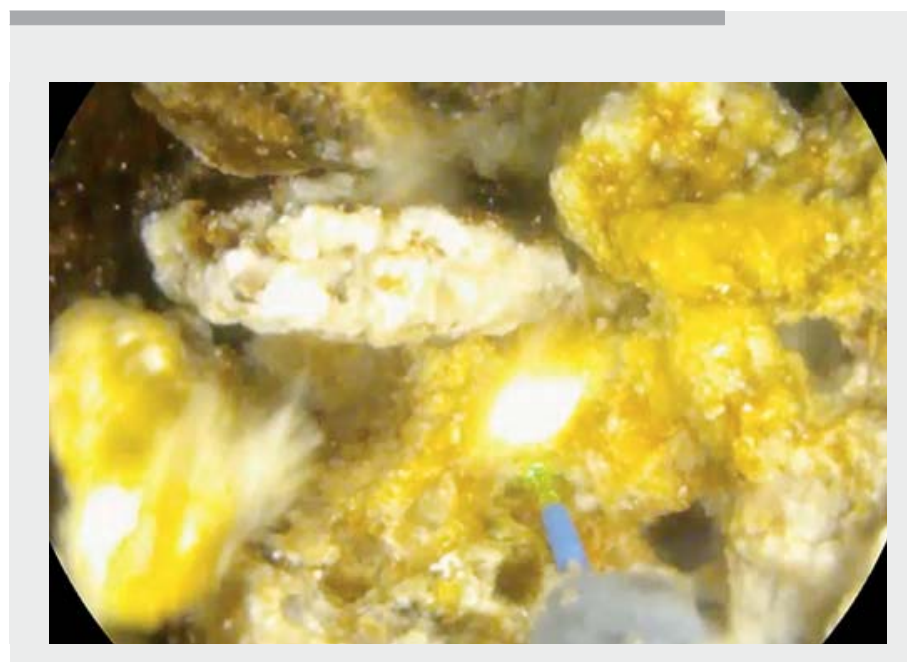

$\nabla$ Video 1 Endoscopic view of holmium laser lithotripsy of the central part of one of the stones inside the gallbladder.

An 80-year-old woman presented with a 1-year history of recurrent right upper quadrant colicky pain. Her medical history included abdominal surgery, ischemic stroke with impaired mobility, and obesity (body mass index $>30.1 \mathrm{~kg} /$ $\mathrm{cm}^{2}$ ).

Transabdominal ultrasound showed distended gallbladder with thickened walls and two large stones $(4 \mathrm{~cm}$ and $3 \mathrm{~cm})$. Endoscopic ultrasound-guided gallbladder drainage (EUS-GBD) followed by intracholecystic lithotripsy was offered as a minimally invasive treatment alternative to surgery and scheduled for 2 weeks later.

EUS examination confirmed gallbladder wall thickening and two large stones ( Video 1). Transduodenal EUS-GBD using a $15 \times 10 \mathrm{~mm}$ AXIOS stent (Boston Scientific, Marlborough, Massachusetts, USA) mounted onto a cautery device was successfully performed (
After 48 hours, the central stent was dilated up to $15 \mathrm{~mm}$ and the gallbladder lumen accessed with a gastroscope. After adequate water irrigation, holmium laser lithotripsy with variable pulse power and frequencies was performed [1], and fragmented stones were flushed out or removed using a Dormia basket or Roth net until complete gallbladder clearance was achieved (\$Fig. 2). No adverse events occurred and the patient was discharged.

Outpatient cholecystoscopy 2 weeks later revealed complete gallbladder clearance. The stent was removed using a grasping forceps (> Fig.3) and exchanged for two double-pigtail stents $(7 \mathrm{Fr}, 4 \mathrm{~cm})$, which were left in place ( Fig. 4).

Elective endoscopic gallbladder treatment has been described previously in five relatively young patients with a mean age of 50 years and giant gall-

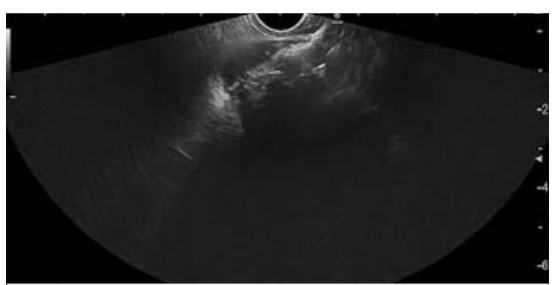

- Fig. 1 Endoscopic ultrasound view of the distal flange of the AXIOS stent (Boston Scientific, Marlborough, Massachusetts, USA) opened inside the gallbladder after pushing one of the stones forward.

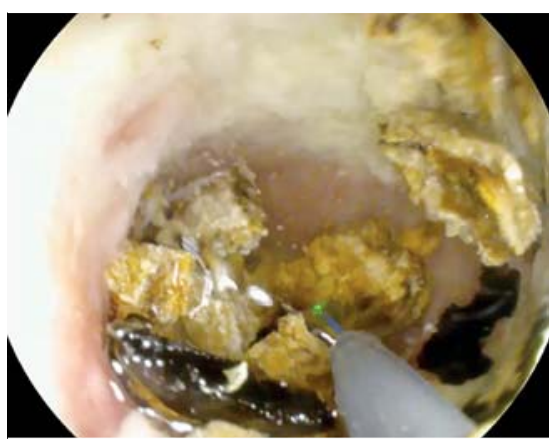

Fig. 2 Endoscopic view of holmium laser lithotripsy of the stone fragments inside the gallbladder.

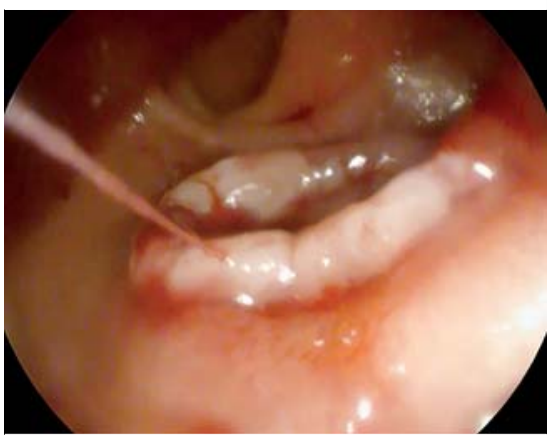

Fig. 3 Endoscopic view of the gastric side of the fistulous tract after removal of the AXIOS stent (Boston Scientific, Marlborough, Massachusetts, USA). 


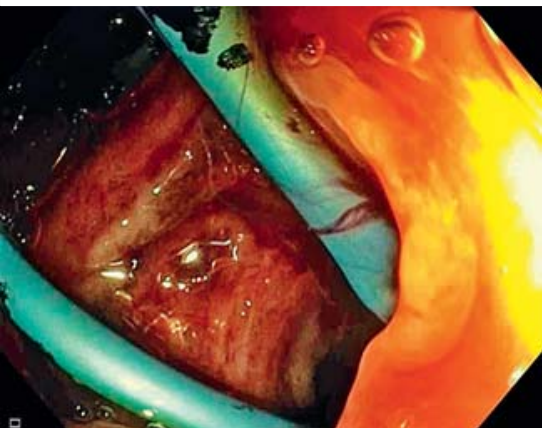

- Fig. 4 Endoscopic view of the two double-pigtail stents placed from the stomach into the gallbladder through the fistulous tract.

stones, who rejected surgery and desired gallbladder preservation [2]. With an aging population, the number of elderly frail individuals at high surgical risk and gallstone disease requiring surgical intervention is expected to increase [3], and elective endoscopic gallbladder treatment may be a valid alternative treatment option in such patients.

Endoscopy_UCTN_Code_TTT_1AS_2AD

\section{Competing interests}

Dr. Larghi is a consultant for Boston Scientific Corp. and Pentax Medical. He has also received research support from Medtronic. All other authors declare that they have no conflict of interest.
Mario Gagliardi ${ }^{1}{ }^{\oplus}$, Gianenrico Rizzatti ${ }^{1,2}$, Michele Impagnatiello ${ }^{3}$, Alberto Larghi ${ }^{1,2}$

1 Digestive Endoscopy Unit, Fondazione Policlinico Universitario A. Gemelli IRCCS, Rome, Italy

2 CERTT, Center for Endoscopic Research Therapeutics and Training, Catholic University, Rome, Italy

3 Internal Medicine, Gastroenterology and Hepatology, Fondazione Policlinico Universitario A. Gemelli IRCCS, Rome, Italy

\section{Corresponding author}

\section{Alberto Larghi, MD, PhD}

Digestive Endoscopy Unit, Fondazione Policlinico Universitario A. Gemelli IRCCS, Largo A. Gemelli 8, 00168 Rome, Italy alberto.larghi@policlinicogemelli.it

\section{References}

[1] Larghi A, Rimbas M, Attili F et al. Endoscopic holmium laser lithotripsy of symptomatic gallstones through a lumen-apposing selfexpandable metal stent. Am J Gastroenterol 2016; 111: 1516

[2] Wang W, Liu B, Qi K et al. Efficacy and safety of endoscopic laser lithotripsy and lithotomy through the lumen-apposing metal stent for giant gallbladder stones. VideoGIE 2020; 5 : 318-323

[3] Chhoda A, Mukewar SS, Mahadev S. Managing gallstone disease in the elderly. Clin Geriatr Med 2021; 37: 43-69

\section{Bibliography}

Endoscopy 2022; 54: E437-E438

DOI 10.1055/a-1625-3902

ISSN 0013-726X

published online 17.9.2021

(c) 2021. Thieme. All rights reserved.

Georg Thieme Verlag KG, Rüdigerstraße 14, 70469 Stuttgart, Germany

\section{ENDOSCOPY E-VIDEOS \\ https://eref.thieme.de/e-videos}

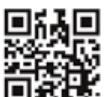

Endoscopy E-Videos is an open access online section, reporting on interesting cases and new techniques in gastroenterological endoscopy. All papers include a high quality video and all contributions are freely accessible online. Processing charges apply (currently EUR 375), discounts and wavers acc. to HINARI are available.

This section has its own submission website at https://mc.manuscriptcentral.com/e-videos 